\title{
APPLICATION OF INTRATHECAL BACLOFEN IN BRAIN INJURY AND DISORDER OF CONSCIOUSNESS. A CASE REPORT.
}

\author{
Andrés Rodriguez Salvador ${ }^{1}$, Gabriela Espigares Correa ${ }^{1}$, Miguel David Membrilla Mesa ${ }^{1}$, Gracia María Ábalos Medina ${ }^{1}$, Jesús Benito Penalva², \\ Inmaculada García Montes ${ }^{1}$. \\ ${ }^{1}$ Physical Medicine and Rehabilitation Department. Hospital Universitario Virgen de las Nieves, Granada, Spain \\ 2 Institut Guttmann, Badalona, Spain.
}

Introduction: Severe brain injured
patients with spasticity resistent to
maximal doses of oral antispastics,
are eligible to introduce Intrathecal
Baclofen (IB). Some authors described
an improvement in the level of
consciousness (LOC) in patients with
brain injury (BI), treated with IB for
spasticity or disautonomy.

Introduction: Severe brain injured patients with spasticity resistent to maximal doses of oral antispastics, are eligible to introduce Intrathecal Baclofen (IB). Some authors described an improvement in the level of brain injury $(\mathrm{BI})$, treated with $\mathrm{IB}$ for spasticity or disautonomy.

Purpose: We present a
case report of a patient
with brain injury who
experimented an
improvement in the LOC
after IB.

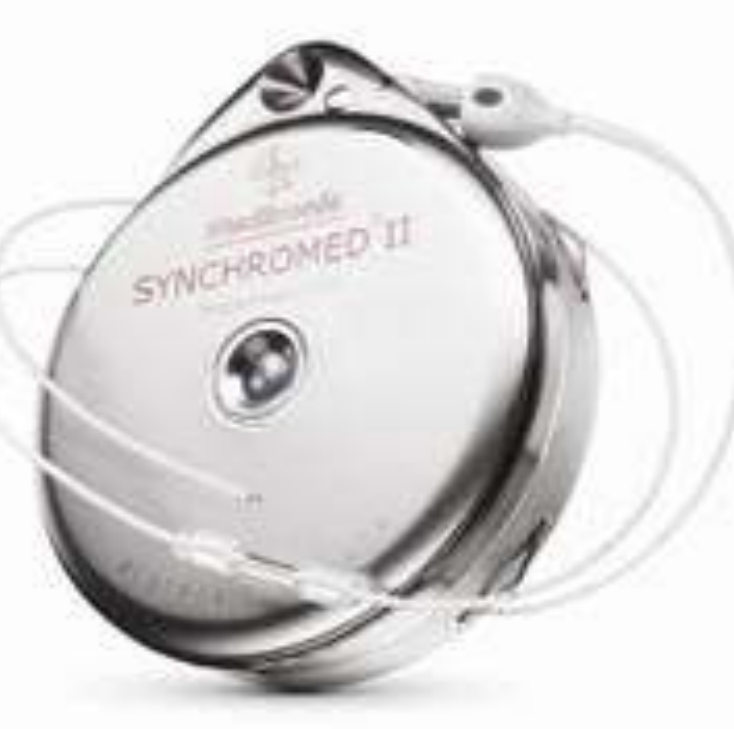

Method: 42-years old woman who suffered ischemic cerebral stroke admitted at hospital in 2016. She presented spasticity and Minimal Conscious State (MCS) for 10 months. Maximal dose of oral antispastics were administrated without success (Modified Ashworth ScaleMAS- of 4), so IB test was indicated. The first test with $50 \mathrm{mcg}-100 \mathrm{mcg}$ was not successful. After that, she was underwent one week IB test through an external catheter. We scored the spasticity with MAS and the LOC with the Coma Recovery Scale- Revised (CRS-R). The final IB pump was implanted in the 11th month after onset.
Results: Apart of the improvement in the spasticity with MAS 3, we observed an unexpected improvement in the LOC: obeyed simple commands, sayed some intentional words. We scored de LOC with CRS-R during the one-week IB infusion test and compared with previous scoring (Ilustration 1). Unfortunatelly, no CRS-R was registred when we observed the most improvement in LOC. Few days after the external catheter was removed, the LOC returned to the previous state. Due the positive results, IB pump was finally implanted and the patient reached a better LOC. Modafinilo was administrated some days before the first IB infusion, but we do not correlate it with the improvement of LOC, because it was evident only with IB and desapeared when IB was stopped even with modafinilo.

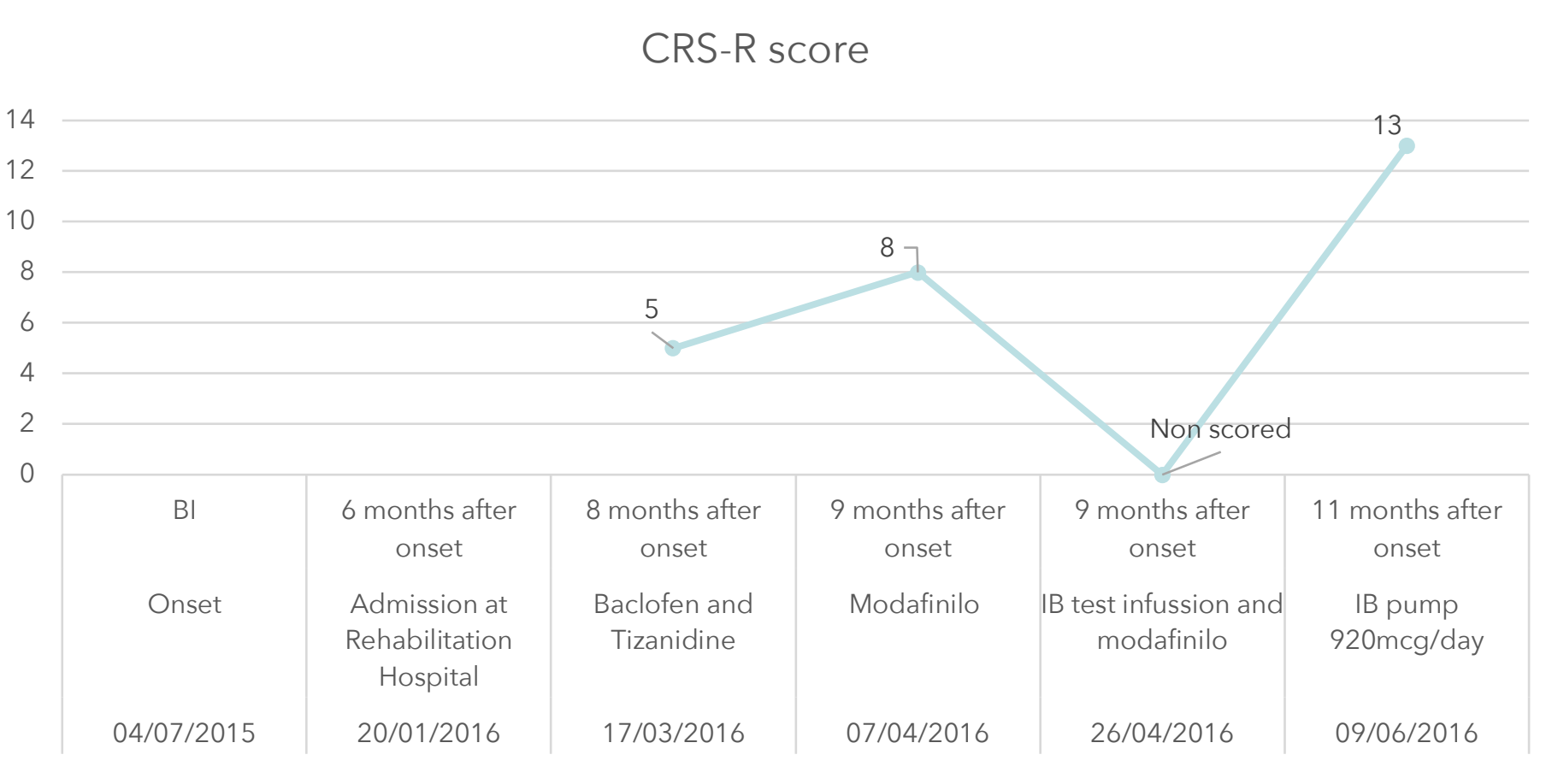

Ilustration 1

Conclusion: IB is indicated in patients with brain injury for spasticity. We suggest the LOC as a possible outcome after IB. There is an important lack of evidence to recommend it but it is necessary to have it into account for future perspectives.

\footnotetext{
Bibliography:

1. Taira T, Hori T. Clinical application of drug pump for spasticity, pain, and restorative neurosurgery: other clinical applications of intrathecal baclofen. Acta Neurochir Suppl. 2003;87:37-8.

2. Guerriero RM, Giza CC, Rotenberg A. Glutamate and GABA imbalance following traumatic brain injury. Curr Neurol Neurosci Rep. 2015 May; 15(5):27.

3. Sarà M, Pistoia F, Mura E, Onorati P, Govoni S. Intrathecal baclofen in patients with persistent vegetative state: 2 hypotheses. Arch Phys Med Rehabil. 2009 Jul;90(7):1245-9.

4. Sarà M, Sacco S, Cipolla F, Onorati P, Scoppetta C, Albertini G, et al. An unexpected recovery from permanent vegetative state. Brain Inj. 2007 Jan;21(1):101-3.

5. Oyama H, Kito A, Maki H, Hattori K, Tanahashi K. Consciousness recovery induced by intrathecal baclofen administration after subarachnoid hemorrhage -two case reports-. Neurol Med Chir (Tokyo). 2010;50(5):386-90.

6. Al-Khodairy AT, Wicky G, Nicolo D, Vuadens P. Influence of intrathecal baclofen on the level of consciousness and mental functions after extremely severe traumatic brain injury: brief report. Brain Inj. 2015;29(4):527-32.

7. Asahi T, Kashiwazaki D, Koh M, Matsumura N, Kuroda S. [Complete remission of consciousness disturbances and spasticity due to a severe subarachnoid hemorrhage after intrathecal baclofen therapy: a case report]. No Shinkei Geka. 2015 Mar;43(3):253-7.

8. Margetis K, Korfias SI, Gatzonis S, Boutos N, Stranjalis G, Boviatsis E, et al. Intrathecal baclofen associated with improvement of consciousness disorders in spasticity patients. Neuromodulation J Int Neuromodulation Soc. 2014 Oct; 17(7):699-704: discussion 704

9. Hoarau X, Richer E, Dehail P, Cuny E. Comparison of long-term outcomes of patients with severe traumatic or hypoxic brain injuries treated with intrathecal baclofen therapy for dysautonomia. Brain Inj. 2012;26(12):1451-63.

10. Georgiopoulos M, Katsakiori P, Kefalopoulou Z, Ellul J, Chroni E, Constantoyannis C. Vegetative state and minimally conscious state: a review of the therapeutic interventions. Stereotact Funct Neurosurg. 2010;88(4):199-207.

11. Motokizawa F, Fujimori B. AROUSAL EFFECT OF AFFERENT DISCHARGES FROM MUSCLE SPINDLES UPON ELECTROENCEPHALOGRAMS IN CATS. JPn J Physiol. 1964 Aug 15;14:344-53. 11. Wotokizawa F, Fujimori B. AROUSAL EFFECT OF AFFERENT DISCHARGES FROM MUSCLE SPINDLES UPON ELECTROENCEPHALOG

12. Wolf ME, Keener S, Mathis P, Mosnaim AD. Phenylethylamine-like properties of baclofen. Neuropsychobiology. 1983;9(4):219-22.
13. Margetis K, Markianos M, Gatzonis S, Kalamatianos T, Sakas D. Effects of intrathecal baclofen therapy on CSF neurotransmitter metabolite levels. J Clin Psychopharmacol. 2014 Feb;34(1):171-4. 13. Margetis K, Markianos M, Gatzonis S, Kalamatianos T, Sakas D. Effects of intrathecal baclofen therapy on CSF neu

15. Huang H, Ghosh P, Pol AN van den. Prefrontal Cortex-Projecting Glutamatergic Thalamic Paraventricular Nucleus-Excited by Hypocretin: A Feedforward Circuit That May Enhance Cognitive Arousal. J Neurophysiol. 2006 Mar 1;95(3):1656-68.
} 